\title{
Acceptance of orthodontic miniscrews as temporary anchorage devices
}

This article was published in the following Dove Press journal:

Patient Preference and Adherence

30 June 2014

Number of times this article has been viewed

\author{
Khalid H Zawawi \\ Department of Orthodontics, \\ Faculty of Dentistry, King Abdulaziz \\ University, Jeddah, Saudi Arabia
}

Objective: To study the patient's acceptance, expectation, and experience of pain with orthodontic temporary miniscrews.

Methods: Questionnaires were distributed to 165 potential temporary orthodontic miniscrew recipients or their parents. Using the numeric rating scale, patients who received miniscrews as part of their orthodontic treatment were also asked to rate the pain or discomfort experience after miniscrew placement.

Results: A total of 165 subjects completed the first set of questions. There was a significant relationship between level of education and prior knowledge about orthodontic miniscrews $(P=0.029)$. Even though only $12.7 \%$ had heard about miniscrews, $82.4 \%$ agreed to have miniscrews placed to facilitate orthodontic tooth movement. Eighty-three subjects who needed miniscrews as part of their orthodontic treatment completed two more sets of questions after 6 and 24 hours of miniscrew insertion. After 6 hours of miniscrew insertion, there was a significant difference in pain perception between men $($ mean $=2.6 \pm 2.2)$ and women $($ mean $=2.1 \pm 1.5 ; P=0.03)$. After 24 hours, there was no difference between men $(0.2 \pm 0.4)$ and women $(0.2 \pm 0.5 ; P>0.05)$. Postplacement, $32.5 \%$ did not require any pain medication, while $59.1 \%$ required a single dose and only $8.4 \%$ required two doses. A total of 76 patients $(91.6 \%)$ said that they would recommend this procedure.

Conclusion: Patients do accept miniscrew as a treatment option in orthodontics. Postoperative pain is significantly low. The acceptance of miniscrews was not related to patient's previous knowledge of the device, and patients preferred miniscrews to extractions.

Keywords: orthodontic treatment, miniscrew, temporary anchorage device, patient acceptance

\section{Introduction}

Conventionally, orthodontists used a vast array of armamentarium to control anchorage and achieve required tooth movement. Based on Newton's third law, anchorage units experience an equal and opposite force. Negating this reciprocal force has been and still is the focus of biomechanical considerations and research in orthodontics. Anchorage planning and preparation before any tooth movement is started is essential to prevent untoward tooth movements and not to compromise the orthodontic result. ${ }^{1}$ In an effort to prevent these complications, skeletal anchorage has been progressively integrated into orthodontic treatment. ${ }^{2}$ Recently, great importance has been placed on the miniscrew type of temporary anchorage device for orthodontic purposes. ${ }^{3-7}$ These miniscrews are relatively small to implant with a simple surgical procedure. ${ }^{8}$ Miniscrews are commercially available in a number of sizes (width and lengths), they can also easily be inserted and removed, they can be loaded immediately, and they are relatively cost-effective. ${ }^{1,9}$ Furthermore, technical advances in miniscrew design have led to a decrease in discomfort and chair time during their placement.

Even though the added cost is not an issue to patients, the possibility of additional discomfort together with fear could change their decision when choosing between
Department of Orthodontics, Faculty of Dentistry, King Abdulaziz University, PO Box 80209, Jeddah 21589,

Saudi Arabia

Tel +966-2 6402000 , ext 20388

Fax +966-2 6403316

Email kzawawi@kau.edu.sa 
miniscrews and other intra/extraoral orthodontic appliances. This fear of possible pain and discomfort resulting from the added surgical procedure could be a problem, as it can contribute to the patient avoiding orthodontic treatment. ${ }^{10}$ It has been documented that patients do, in fact, complain about discomfort and pain during orthodontic treatment. ${ }^{1-14}$ However, little is known about the pain associated with miniscrews and how it compares with pain experienced from other orthodontic procedures. Greater understanding of the pain experienced as a result of different orthodontic procedures is of great importance. The knowledge of treatment perception can also help provide patients with realistic expectations of the likely pain that may be encountered during orthodontic treatment, and accordingly, can help educate for informed consent. ${ }^{15}$ In addition, it can provide an insight into the acceptance of this novel orthodontic anchorage device. In view of the limited reports regarding postoperative discomfort and pain after placing orthodontic miniscrews, this study aimed to determine patients' experiences of pain associated with the placement of miniscrews and to compare their experiences of pain. In addition, it sought to assess patients' acceptance of miniscrews as a new anchorage device.

\section{Materials and methods}

This study was conducted at the Faculty of Dentistry, King Abdulaziz University, Jeddah, Saudi Arabia, and at a private office. Patients seeking orthodontic treatment were asked to complete a set of questionnaires regarding orthodontic treatment and temporary orthodontic miniscrews, and subjects who required miniscrew placement as part of their orthodontic treatment plan were asked to complete another set of questions that comprised a 10-point numerical rating scale (NRS) for pain, with 0 being no pain and 10 being the maximum pain felt; number of time analgesics were used; and whether they would recommend this treatment to other patients. ${ }^{16}$ Before miniscrew placement, the advantages, disadvantages, and potential complications of the minor procedure were explained to the patients or their parents. All questionnaires were anonymous, and no personal information was gathered. The study was reviewed and approved by the Research Ethics Committee at the Faculty of Dentistry, King Abdulaziz University, and an informed consent was obtained.

OrthoEasy system (Forestadent, Pforzheim, Germany) self-tapping self-drilling miniscrews were used. In the maxilla, a $8 \mathrm{~mm}$ long miniscrew was used, and a $6 \mathrm{~mm}$ long one was used in the mandible. The width was $1.8 \mathrm{~mm}$ for both. One operator placed all miniscrews under local anesthesia.
The location was determined with the aid of periapical and bitewing X-rays, using a metal jig. No mucoperiosteal flap was raised, and no pilot hole was required. After administering local anesthetic, miniscrews were placed manually through the attached gingival. Patients were requested to inform the operator if any discomfort was felt during the procedure. Postsurgically, miniscrew position was verified by taking periapical and bitewing radiographs. All miniscrews were loaded using power chains, with an average of $120 \mathrm{gm}$ of force, and the patients were instructed to take an analgesic before the local anesthetic diminishes, and more if needed. They were instructed to keep a diary on how many times they needed to take an analgesic. The patients were recalled after 4 weeks for their orthodontic follow-up visit.

\section{Statistical analysis}

Data analysis was performed using the Statistical package for Social Sciences version 20 (SPSS; IBM Corporation, Armonk, NY, USA). Frequencies for each answer to the questionnaires were calculated using the number of subjects responding to each question. Comparison of data between both groups was performed using the chi square tests for nominal data and the independent Student's $t$-test for continuous data. The level of statistical significance was considered at $P<0.05$.

\section{Results}

A total of 165 subjects, mean age, $21.4( \pm 4.1)$ years, 52 men and 113 women, completed the first set of questions. A summary of the responses is presented in Table 1.

Chi square analyses showed that there was no significant relationship between any of the variables in Table 1 except for level of education and prior knowledge about orthodontic miniscrews $(P=0.029)$.

It was of interest to note that even though only $12.7 \%$ of the participants had heard about miniscrews before, $82.4 \%$ agreed to have miniscrews used to facilitate orthodontic tooth movement.

From the 165 subjects who completed the first set of questions (Table 1), only 83 (29 men and 54 women) needed miniscrews as part of their orthodontic treatment. These patients completed two more sets of questions. After 6 hours of miniscrew insertion, the mean perception of pain based on the NRS scores was $2.3( \pm 1.8)$. There was a significant difference in pain perception between men (mean $=2.6 \pm 2.2)$ and women (mean $=2.1 \pm 1.5 ; P=0.03$ ). Twenty-four hours from the procedure, the mean pain experience was $0.22( \pm 0.5)$, with no differences between men $(0.2 \pm 0.4)$ and women $(0.2 \pm 0.5 ; P>0.05)$. 
Table I Summary of the results of the questionnaires given initially

\section{Question}

Level of education

Who is the patient?

Who referred you for orthodontics?

Why do you seek orthodontic care?

Would you like to straighten your teeth?

Would the cost of orthodontic treatment be a concern?

Would you agree to extractions in order to straighten your teeth?

Would the number of extracted teeth matter?

Orthodontics is a long treatment process; is time a concern to you?

Would having pain, soreness, and discomfort put you off the idea of having braces?

Are you willing to be cooperative (elastic wear, oral hygiene, head gear, appointments)?

Did you hear about miniscrews for orthodontic treatment before?

Would you agree to have temporary orthodontic miniscrews to facilitate tooth movement and reduce treatment time?

Would you choose temporary orthodontic miniscrews over extractions?

Is the cost of temporary orthodontic miniscrews a concern?

Would you agree to place temporary orthodontic miniscrews for your child as a treatment option?

If temporary orthodontic miniscrews were the only option, would you agree?

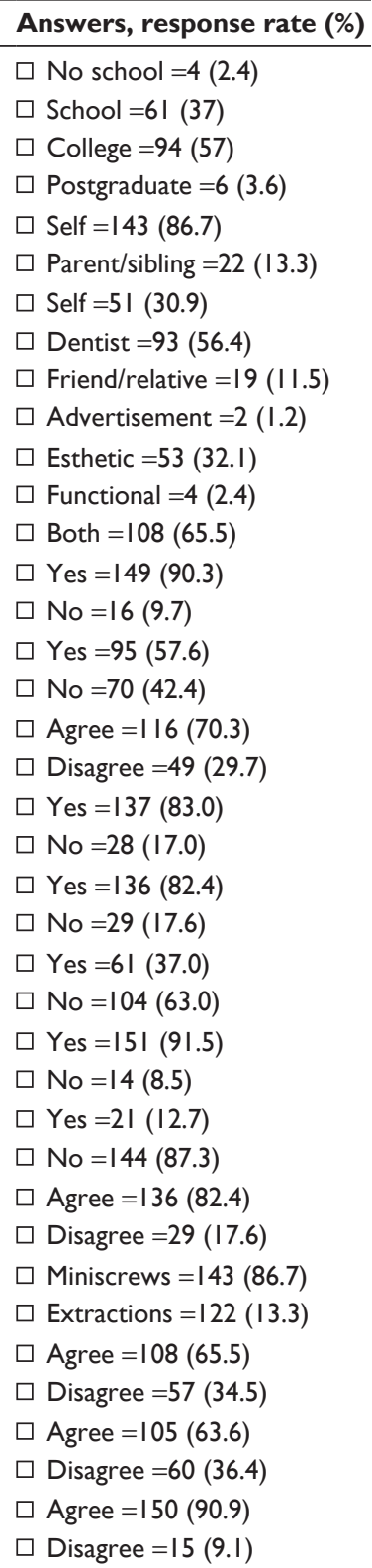

The number of times the patients took an analgesic after miniscrew insertion is presented in Table 2.

During the follow-up appointment, patients were asked whether they would recommend temporary orthodontic miniscrews to others. A total of 76 patients $(91.6 \%)$ said that

Table 2 Number of times the patients took analgesics within 24 hours of miniscrew insertion

\begin{tabular}{llll}
\hline Sex & \multicolumn{4}{l}{ Number of times an analgesic was used } \\
\cline { 2 - 4 } & None & Once & Twice \\
\hline Men & 7 & 18 & 4 \\
Women & 20 & 31 & 3 \\
Total & 27 & 49 & 7 \\
\hline
\end{tabular}

they would recommend this procedure, including 53 (98.2\%) men and 23 (79.3\%) women.

\section{Discussion}

Limited articles have focused on patients' experience relative to their expectations and acceptance for orthodontic treatment with miniscrews. ${ }^{17-19}$ This, nonetheless, is a critical issue, as such studies do not always offer the results that the clinician may expect. ${ }^{20}$ It is well known that orthodontic treatment requires significant patient compliance ${ }^{21,22}$ and that patient compliance is significantly influenced by experiences such as pain. Orthodontic patients often experience pain during treatment. ${ }^{13}$ Therefore, if orthodontic 
therapy only concentrates on function and occlusion while overlooking the patient's perceptions, it could fail. There are few reports about the pain caused by miniscrews. ${ }^{11,12,17,23,24}$ However, treatment efficacy and the level to which patients are capable or prepared to accept the proposed treatment steps should be addressed. ${ }^{17}$ The NRSs are a particularly useful and validated index to evaluate pain and symptoms during treatment.

Temporary orthodontic miniscrews are becoming widely used because of their ability to provide skeletal anchorage and to reduce the necessity for patient compliance during the course of orthodontic treatment. ${ }^{25}$ To date, limited clinical studies have evaluated implant success and the acceptance of temporary orthodontic miniscrews. The aim of this study was to substantiate patients' acceptance and perception of temporary orthodontic miniscrews. As for the choice of orthodontic treatment, it was interesting to note that $86.7 \%$ chose miniscrews over extraction, even though only $12.7 \%$ had prior knowledge of the screws. This result is in agreement with a previous finding in which $90 \%$ of patients selected miniscrews over extractions. ${ }^{19}$ This supports the idea that the miniscrews are a practical appliance in which patient compliance is not essential and facilitates orthodontic treatment without the need for extractions with a successful treatment outcome. ${ }^{17}$

Pain affects both quality of life and treatment cooperation. ${ }^{26}$ The feeling of pain is considered a subjective parameter. ${ }^{18}$ When asked about pain felt after placement of the miniscrew, only 4 (4.8\%) patients of a total of 83 had an NRS score of more than 5. It is worthy to note that $32.5 \%$ of the patients did not require any pain medication postplacement, $59.1 \%$ required a single dose of an analgesic after the procedure, and only $8.4 \%$ needed to take analgesics twice postinsertion. Almost all patients who received miniscrews would recommend the procedure to a friend (91.6\%) and had no complaints.

\section{Conclusion}

On the basis of the patients' responses, it can be concluded that patients do accept miniscrews as a treatment option in orthodontics; postoperative pain is significantly low, as $32.5 \%$ of the participants did not require any pain medication postminiscrew placement and $59.1 \%$ required only a single dose of an analgesic. In addition, there were no differences between the sexes in the overall pain experienced after 24 hours of miniscrew placement, and the acceptance of miniscrews was not related to a patient's previous knowledge of the device. Finally, patients preferred miniscrews to extractions.

\section{Disclosure}

The author reports no conflicts of interest in this work.

\section{References}

1. Cope J. Temporary anchorage devices in orthodontics: a paradigm shift. Semin Orthod. 2005;11(1):3-9.

2. Creekmore TD, Eklund MK. The possibility of skeletal anchorage. J Clin Orthod. 1983;17(4):266-269.

3. Kanomi R. Mini-implant for orthodontic anchorage. J Clin Orthod. 1997;31(11):763-767.

4. Kuroda S, Katayama A, Takano-Yamamoto T. Severe anterior open-bite case treated using titanium screw anchorage. Angle Orthod. 2004;74(4): 558-567.

5. Al-Fraidi AA, Zawawi KH. Clinical showcase. Selective intrusion of overerupted upper first molars using a temporary anchorage device: case report. J Can Dent Assoc. 2010;76:a9.

6. Aljhani A, Zawawi KH. The use of mini-implants in en masse retraction for the treatment of bimaxillary dentoalveolar protrusion. Saudi Dent J. 2010;22(1):35-39.

7. Aljhani AS, Zawawi KH. Nonextraction treatment of severe crowding with the aid of corticotomy-assisted orthodontics. Case Rep Dent. 2012; 2012:694527.

8. Park HS, Bae SM, Kyung HM, Sung JH. Micro-implant anchorage for treatment of skeletal Class I bialveolar protrusion. J Clin Orthod. 2001; 35(7):417-422.

9. Fritz U, Ehmer A, Diedrich P. Clinical suitability of titanium microscrews for orthodontic anchorage-preliminary experiences. J Orofac Orthop. 2004;65(5):410-418.

10. Oliver RG, Knapman YM. Attitudes to orthodontic treatment. $\mathrm{Br} J$ Orthod. 1985;12(4):179-188.

11. Bergius M, Berggren U, Kiliaridis S. Experience of pain during an orthodontic procedure. Eur J Oral Sci. 2002;110(2):92-98.

12. Bergius M, Kiliaridis S, Berggren U. Pain in orthodontics. A review and discussion of the literature. J Orofac Orthop. 2002;61(2):125-137.

13. Erdinç AM, Dinçer B. Perception of pain during orthodontic treatment with fixed appliances. Eur J Orthod. 2004;26(1):79-85.

14. Firestone AR, Scheurer PA, Bürgin WB. Patients' anticipation of pain and pain-related side effects, and their perception of pain as a result of orthodontic treatment with fixed appliances. Eur J Orthod. 1999;21(4): 387-396.

15. Casarett D, Karlawish J, Sankar P, Hirschman KB, Asch DA. Obtaining informed consent for clinical pain research: patients' concerns and information needs. Pain. 2001;92(1-2):71-79.

16. Gagliese L, Weizblit N, Ellis W, Chan VW. The measurement of postoperative pain: a comparison of intensity scales in younger and older surgical patients. Pain. 2005;117(3):412-420.

17. Feldmann I, List T, Feldmann H, Bondemark L. Pain intensity and discomfort following surgical placement of orthodontic anchoring units and premolar extraction: a randomized controlled trial. Angle Orthod. 2007;77(4):578-585.

18. Cornelis MA, Scheffler NR, Nyssen-Behets C, De Clerck HJ, Tulloch JF. Patients' and orthodontists' perceptions of miniplates used for temporary skeletal anchorage: a prospective study. Am J Orthod Dentofacial Orthop. 2008;133(1):18-24.

19. Blaya MG, Blaya DS, Guimarães MB, Hirakata LM, Marquezan M. Patient's perception on mini-screws used for molar distalization. Rev Odonto Ciênc. 2010;25(3):266-270.

20. Baxmann M, McDonald F, Bourauel C, Jäger A. Expectations, acceptance, and preferences regarding microimplant treatment in orthodontic patients: A randomized controlled trial. Am J Orthod Dentofacial Orthop. 2010;138(3):250.e1-e250.e10.

21. Bos A, Hoogstraten J, Prahl-Andersen B. Towards a comprehensive model for the study of compliance in orthodontics. Eur J Orthod. 2005;27(3):296-301. 
22. Johnson PD, Cohen DA, Aiosa L, McGorray S, Wheeler T. Attitudes and compliance of pre-adolescent children during early treatment of Class II malocclusion. Clin Orthod Res. 1998;1(1):20-28.

23. Abu-Saad H. Assessing children's responses to pain. Pain. 1984;19(2): $163-171$.

24. Lee TC, McGrath CP, Wong RW, Rabie AB. Patients' perceptions regarding microimplant as anchorage in orthodontics. Angle Orthod. 2008; 78(2):228-233.
25. Papadopoulos MA, Tarawneh F. The use of miniscrew implants for temporary skeletal anchorage in orthodontics: a comprehensive review. Oral Surg Oral Med Oral Pathol Oral Radiol Endod. 2007;103(5):e6-e15.

26. Krukemeyer AM, Arruda AO, Inglehart MR. Pain and orthodontic treatment. Angle Orthod. 2009;79(6):1175-1181.

\section{Publish your work in this journal}

Patient Preference and Adherence is an international, peer-reviewed, open access journal that focusing on the growing importance of patient preference and adherence throughout the therapeutic continuum. Patient satisfaction, acceptability, quality of life, compliance, persistence and their role in developing new therapeutic modalities and compounds to optimize clinical outcomes for existing disease states are major areas of interest for the journal. This journal has been accepted for indexing on PubMed Central. The manuscript management system is completely online and includes a very quick and fair peer-review system, which is all easy to use. Visit http://www. dovepress.com/testimonials.php to read real quotes from published authors.

\footnotetext{
Submit your manuscript here: http://www.dovepress.com/patient-preference-and-adherence-journal
} 